\title{
TWO FSP SYNTHESIS OF EIGHT LINK GEAR MECHANISM FOR MOTION GENERATION WITH 9R-1G JOINTS
}

\author{
H. M. Naveen \\ Assistant Professor, \\ Department of Mechanical \\ Engineering, RYM \\ Engineering College, \\ Ballari, Karnataka, India
}

\author{
Shrinivas S. Balli \\ Professor \& Head, \\ Department of Mechanical \\ Engineering, Basaveshwar \\ Engineering College, \\ Bagalkot, Karnataka, India
}

\author{
Umesh M. Daivagna \\ Professor, Department of \\ Mechanical Engineering, \\ Ballari Institute of \\ Technology, Ballari, \\ Karnataka, India
}

\begin{abstract}
The paper presents a mechanism consisting of nine revolute and one gear joints. A planar eight link gear mechanism having two degrees of freedom is considered for synthesis using variable topology method operating in two phases for the task of motion generation. Complex number method is presented as an ideal tool for synthesizing the linkage. Seven link gear mechanism is considered as a portion of eight link gear mechanism in each phase and illustrated with an example. These seven link gear mechanism portions of eight link gear mechanism are designed for two finitely separated positions. Variable topology method focuses on a non-iterative and simplified way of mechanism synthesis.
\end{abstract}

Keywords: Kinematic Synthesis; Eight Link Gear; Variable Topology

\section{INTRODUCTION}

Kinematic synthesis of mechanisms using the concept of dimensional synthesis is an important part of synthesis process. When number of links and degree of freedom increase the synthesis becomes difficult. Multi-loop mechanisms, adjustable mechanisms and variable topology mechanisms are some of the considerations in methods to synthesize such complicated mechanisms. In this paper a planar eight link gear mechanism with two degrees of freedom is considered for synthesis using variable topology method.

A planar eight link gear mechanism with variable topology is a mechanism working in two different phases with one degree of freedom in each of its phases. In each phase a link next to permanently fixed link of eight link gear mechanism is temporarily fixed and the resulting mechanism becomes like a seven link gear mechanism with one degree of freedom.
This paragraph summarizes the literature review on variable topology method suggesting the footing of the approach adapted by different people working in this area. Balli and Chand (2001) intimated that, an analytical method can be used to synthesize five bar mechanism with variable topology. The work was carried out for movement between extreme positions of the mechanism for function generation. Balli and Chand (2002) proposed the complex number method and utilized it to synthesize the mechanism having five links for motion and path generation tasks with variable topology for movement between extreme positions. Balli and Chand (2003) suggested an analytical method to synthesize planar seven link mechanism with variable topology for motion between two dead centers. Gadad et al., (2005) focused on synthesis of planar seven link mechanism using triad and dyad with variable topology for the task function generation. Daivagna and Balli (2007) dealt with synthesis process of an off-set five link slider mechanism with variable topology. RenChung Soong et al., (2008) applied a geared sevenbar mechanism for mechanical forming presses. Daivagna and Balli (2010) synthesized a variable topology seven-bar slider mechanism to have motion between two dead-center positions. Volkan et al., (2010) presented an analysis and synthesis method for a geared four-bar mechanism. Daivagna and Balli (2011) worked on the synthesis of variable topology mechanism with five-bar slider for finitely separated positions. Prashant and Balli (2019) reviewed the works on variable topology method till date. Rawat (1996) dealt with synthesis of five bar mechanism with variable topology. The need of variable topology is described in the following paragraphs.

A mechanism can be defined as a mechanical device that serves the role of transferring the motion or force from an input link to an output link during the operation (1984). This helps the mechanism to carry out different tasks that may be useful in one or the other way. 


\section{International Journal of Engineering Applied Sciences and Technology, 2020 \\ Vol. 5, Issue 3, ISSN No. 2455-2143, Pages 288-294 \\ Published Online July 2020 in IJEAST (http://www.ijeast.com)}

The mechanism may consist of links or bars connected by joints to form a closed loop. The mechanism may also contain lower pairs, higher pairs or combination of both pairs. Many mechanisms are available having links five and more, with two degree of freedom. Methods to synthesize these mechanisms are also suggested which are cumbersome. In order to cope up with the difficulties faced by kinematicians such mechanisms can be made to operate in two or more phases as suggested by variable topology method and thus synthesis can be carried effortlessly.

\section{VARIABLE TOPOLOGY MECHANISM}

The intention of variable topology method is to simplify the process of synthesis by reducing two degrees of freedom eight link gear mechanism into a single degree of freedom seven link gear mechanism in two phases. The mechanism may be designed to carry out different task in different phases.

Complex number method, one of the analytical synthesis techniques is presented as an ideal tool for modeling linkages with groups of standard form of equations for motion, path and function generation [11]. Hence the method of variable topology using complex number draws the attention of design engineers.

\section{II.I EIGHT LINK GEAR MECHANISM}

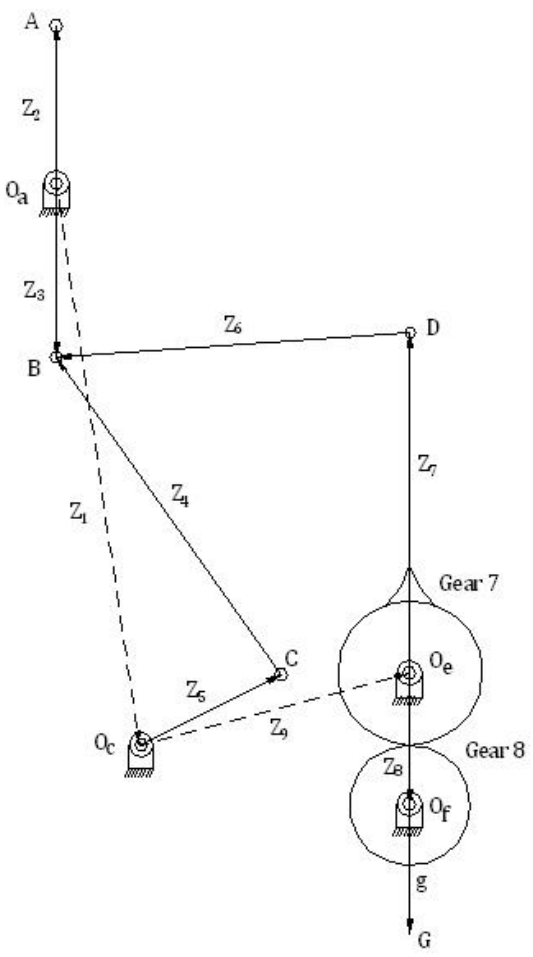

Fig.1 Eight Link Gear Mechanism
The Fig. 1 shows an eight link gear mechanism in which $\mathrm{O}_{\mathrm{a}} \mathrm{A}$ and $\mathrm{O}_{\mathrm{c}} \mathrm{C}$ act as input links of the mechanism. $\mathrm{O}_{a} \mathrm{O}_{c}$ is the fixed ground link. The input links are connected to links $A B$ and CB which in turn are connected to link DB which acts as a coupler. This coupler is connected to gear 7 at point $\mathrm{D}$ which is an extension of gear 7 paired to gear 8 . The extension $\mathrm{O}_{\mathrm{e}} \mathrm{D}$ is fixed to gear 7 and rotates along with it. The gear pair is connected by a rigid link $\mathrm{O}_{\mathrm{e}} \mathrm{O}_{\mathrm{f}}$. The end points of rigid link act as pivot points on which both the gears rotate. When motion is given to any of the input links, it is transferred to the coupler through links $\mathrm{AB}$ and $\mathrm{CB}$ to the link $\mathrm{O}_{\mathrm{e}} \mathrm{D}$ which will rotate according to the desired input motion provided. The vector $\mathrm{g}\left(\mathrm{O}_{\mathrm{f}} \mathrm{G}\right)$ represents the rotation of gear 8 . When gear 7 rotates with angle $\gamma$ then gear 8 will rotate with an angle $\varphi$ in opposite direction with respect to gear 7 . With variable topology method this mechanism can be made to work in different Phases to carry out different tasks. This can be achieved by making one of the input links to be "active" and another input link to be stationary or temporarily fixed.

\section{II.II EIGHT LINK GEAR MECHANISM WITH VARIABLE TOPOLOGY IN PHASE I}

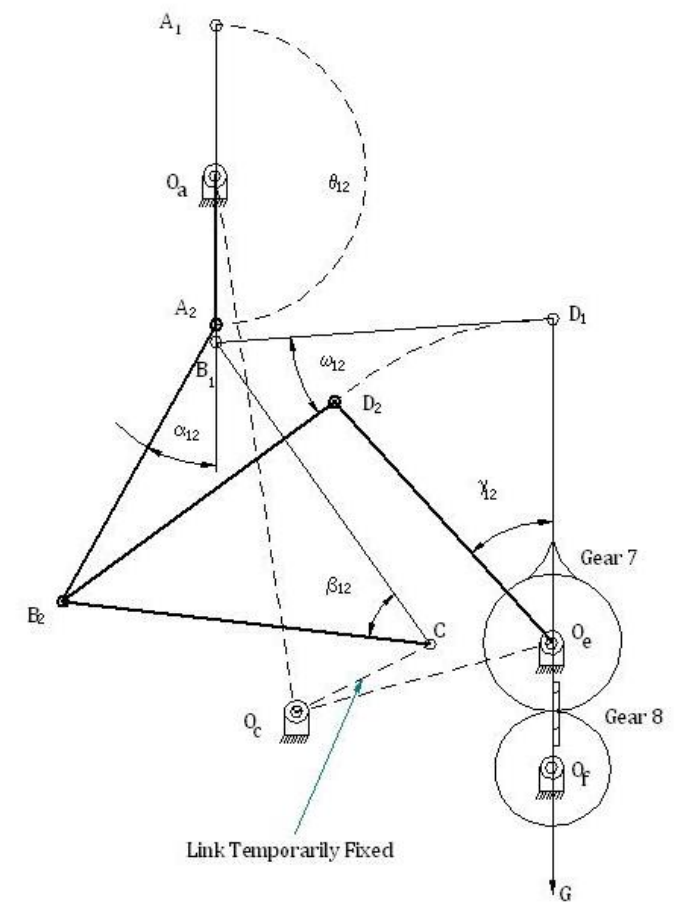

Fig.2 Eight Link Gear Mechanism with Variable Topology Phase I

Position 1: $\mathrm{O}_{\mathrm{a}} \mathrm{A}_{1} \mathrm{~B}_{1} \mathrm{CD}_{1} \mathrm{O}_{\mathrm{e}} \mathrm{O}_{\mathrm{f}}$

Position 2: $\mathrm{O}_{\mathrm{a}} \mathrm{A}_{2} \mathrm{~B}_{2} \mathrm{CD}_{2} \mathrm{O}_{\mathrm{e}} \mathrm{O}_{\mathrm{f}}$

The Fig.2 shows the eight link gear mechanism with variable topology in Phase I. In this phase link $\mathrm{O}_{c} \mathrm{C}$ is temporarily fixed, $\mathrm{O}_{\mathrm{a}} \mathrm{A}$ is the input link. In this Phase, Position 1 is treated as starting position and Position 2 is treated as ending 


\section{International Journal of Engineering Applied Sciences and Technology, 2020 \\ Vol. 5, Issue 3, ISSN No. 2455-2143, Pages 288-294 \\ Published Online July 2020 in IJEAST (http://www.ijeast.com)}

position. When the input link $\mathrm{O}_{\mathrm{a}} \mathrm{A}$ is rotated by $\theta_{12}$ $=-180^{\circ} \mathrm{CW}$ from initial position $\mathrm{O}_{\mathrm{a}} \mathrm{A}_{1}$, this link occupies the new position $\mathrm{O}_{a} \mathrm{~A}_{2}$. Because of this the position of link $A B$ changes from $A_{1} B_{1}$ to $A_{2} B_{2}$. The angle of motion associated with this link will be $\alpha_{12}$. In the same way the positions of link DB will change from $\mathrm{D}_{1} \mathrm{~B}_{1}$ to $\mathrm{D}_{2} \mathrm{~B}_{2}$. Since $\mathrm{O}_{c} \mathrm{C}$ is temporarily fixed, position of link $\mathrm{CB}$ will change from $\mathrm{CB}_{1}$ to $\mathrm{CB}_{2}$. The associated angle of motion for the links will be $\omega_{12}$ and $\beta_{12}$ respectively. As the coupler moves, the gear 7 changes its position from $\mathrm{O}_{\mathrm{e}} \mathrm{D}_{1}$ to $\mathrm{O}_{\mathrm{e}} \mathrm{D}_{2}$ with rotation angle $\gamma_{12}$. Because of this, gear 8 rotates by an angle $\varphi_{12}$. The change in position of the gear 8 can be calculated by considering vector $g\left(\mathrm{O}_{\mathrm{f}} \mathrm{G}\right)$ which represents the rotation of vector.

\section{II.III EIGHT LINK GEAR MECHANISM WITH VARIABLE TOPOLOGY IN PHASE II}

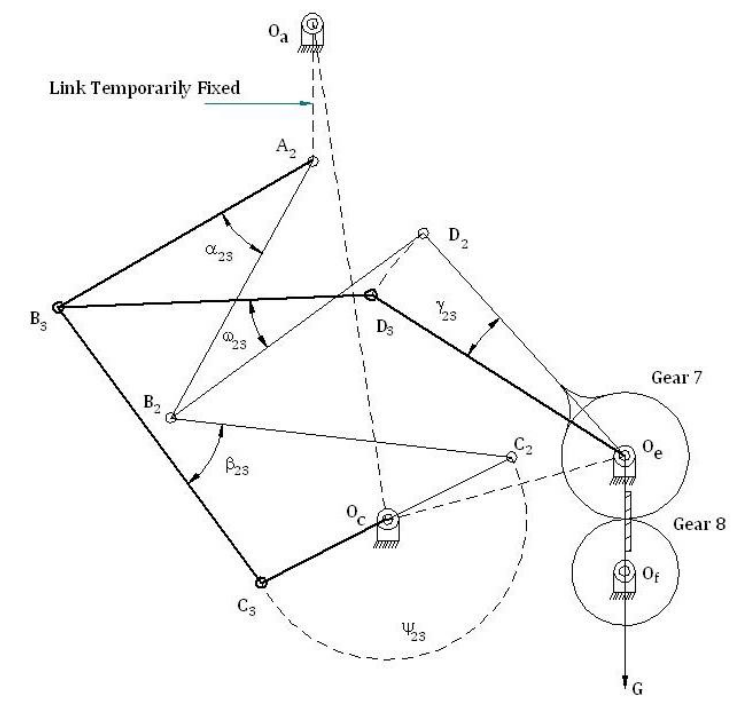

Fig.3 Eight Link Gear Mechanism with Variable Topology Phase II

Position 2: $\mathrm{O}_{\mathrm{c}} \mathrm{C}_{2} \mathrm{~B}_{2} \mathrm{~A}_{2} \mathrm{~B}_{2} \mathrm{D}_{2} \mathrm{O}_{\mathrm{e}} \mathrm{O}_{\mathrm{f}}$

Position 3: $\mathrm{O}_{\mathrm{c}} \mathrm{C}_{3} \mathrm{~B}_{3} \mathrm{~A}_{2} \mathrm{~B}_{3} \mathrm{D}_{3} \mathrm{O}_{\mathrm{e}} \mathrm{O}_{\mathrm{f}}$

The Fig.3 shows the eight link gear mechanism with variable topology in Phase II. In this phase link $\mathrm{O}_{\mathrm{c}} \mathrm{C}_{2}$ which was temporarily fixed in Phase $\mathrm{I}$ is released to move from the initial position 2 to position 3 that is $\mathrm{O}_{\mathrm{c}} \mathrm{C}_{3}$ by an input of $\psi_{23}=-180^{\circ}$ and link $\mathrm{O}_{\mathrm{a}} \mathrm{A}_{2}$ is fixed temporarily. As explained earlier the ending position of Phase I will become starting position of Phase II. The suffixes given to links and angles denote the positions in which they act. Hence, the complete motion of mechanism can be visualized in terms of three positions occurring in different Phases. Positions $1 \& 2$ of the mechanism are related to Phase I and Positions $2 \& 3$ are related to Phase II. These positions are termed as starting and ending positions respectively.

\section{SOLUTION CRITERIA}

\section{a. PHASE I}

In Phase $\mathrm{I}$, the displacement vector $\mathrm{B}_{1} \mathrm{~B}_{2}$ is prescribed to be $\delta_{12}$. The link lengths $Z_{2}, Z_{7}$ and $Z_{8}$ are prescribed. Input crank angle $\theta_{12}$ and rotation of gear $7, \gamma_{12}$ are free choices. The prescribed available are $\alpha_{12}, \beta_{12}$ and $\omega_{12}$. With these conditions the parameters to be determined in Phase I will be link lengths $Z_{3}, Z_{4}$ and $Z_{6}$. Hence, the number of unknowns is three and free choices are two. Thus, the number of solutions reduces to $\infty^{2}$ in Phase I.

\section{b. PHASE II}

In Phase II, $\delta_{23}$ is the displacement vector which is prescribed and $Z_{5}$ is the input link which will be determined. The angles $\alpha_{23}, \beta_{23}$ and $\omega_{23}$ are also prescribed. Hence, $\psi_{23}$ and $\gamma_{23}$ are free choices available. Number of unknown is one and number of solutions reduces to $\infty^{2}$ in this Phase.

Thus, total number of solutions of the phases together will be $\infty^{4}$ for the overall mechanism.

\section{SYNTHESIS OF EIGHT LINK GEAR MECHANISM OF VARIABLE TOPOLOGY TYPE}

\section{IV.I SYNTHESIS OF MECHANISM IN PHASE I}

The mechanism moves from Position 1 to Position 2 in this Phase.

The dyad equation for Phase I is [11] (refer Fig.2) $\mathrm{Z}_{2}\left(\mathrm{e}^{\mathrm{i} \theta 12}-1\right)+\mathrm{Z}_{3}\left(\mathrm{e}^{\mathrm{i} \alpha 12}-1\right)=\delta_{12}$

In the Eq. (1), the prescribed parameters are link length $Z_{2}$, displacement $\delta_{12}=B_{1} B_{2}$ and coupler angle $\alpha_{12}$. Free choices available are $\theta_{12}$ and $\gamma_{12}$. $Z_{3}$ is only unknown parameter and will be determined.

Hence, the unknown parameter is determined by the Eq. (2)

$$
\mathrm{Z}_{3}=\frac{\delta_{12}-\mathrm{Z}_{2}\left(\mathrm{e}^{\mathrm{i} \theta 12}-1\right)}{\left(\mathrm{e}^{\mathrm{i} \alpha 12}-1\right)}
$$

The dyad equation for rest of the links is,

$\mathrm{Z}_{6}\left(\mathrm{e}^{\mathrm{i} \omega 12}-1\right)+\mathrm{Z}_{7}\left(\mathrm{e}^{\mathrm{i} \gamma 12}-1\right)=\delta_{12}$

In the Eq. (3), the prescribed parameters are link length $Z_{7}$, angle $\omega_{12}$ and displacement $\delta_{12}$. Free choice available is $\gamma_{12}$ and $Z_{6}$ is only unknown parameter and will be determined by Eq. (4).

$\mathrm{Z}_{6}=\frac{\delta_{12}-\mathrm{Z}_{7}\left(\mathrm{e}^{\mathrm{i} \gamma 12}-1\right)}{\left(\mathrm{e}^{\mathrm{i} \omega 12}-1\right)}$

The dyad equation,

Let $\mathrm{Z}_{4}\left(\mathrm{e}^{\mathrm{i} \beta 12}-1\right)=\delta_{12}$

In the Eq. (5), the prescribed parameter is displacement $\delta_{12}$ and angle $\beta_{12}$. Z $Z_{4}$ is the only unknown parameter and will be determined by Eq. (6).

$\mathrm{Z}_{4}=\frac{\delta_{12}}{\left(\mathrm{e}^{\mathrm{i} \beta 12}-1\right)}$ 
Hence, the link lengths $Z_{3}, Z_{4}$ and $Z_{6}$ are determined in Phase I.

\section{OUTPUT OF MECHANISM IN PHASE I}

Since the gear 8 acts as an output link the synthesis process in Phase I will be carried out only for seven link mechanism. The rotary motion of gear 7 will be transferred to gear 8 and its motion can be calculated by the Eq. (7). $\mathrm{g}\left(\mathrm{ei}^{\varphi 12}\right)$

In the Eq. (7), $g$ is the vector considered only to represent the position of gear which can be assumed and $\varphi_{12}$ is the angular movement obtained as gear 7 rotates. Hence, gear 8 moves from Position 1(G1) to Position 2(G2).

Link $\mathrm{O}_{\mathrm{e}} \mathrm{O}_{\mathrm{f}}$, is rigid and its end points are the pivot points of gear pair. Vector $Z_{8}$ will be prescribed. Thus, considering all the possibilities, the solution space reduces to $\infty^{3}$ in Phase I.

\section{IV.II SYNTHESIS OF MECHANISM IN PHASE II}

The mechanism moves from Position 2 to Position 3 in this Phase (refer Fig. 3). The displacement vector $\delta_{23}$ can be determined from Eq. (8).

The equation of motion to find the displacement is, (refer Fig.3)

Let, $\quad\left(\mathrm{Z}_{3} \mathrm{e}^{\mathrm{i} \alpha 12}\right)\left(\mathrm{e}^{\alpha 23}-1\right)=\delta_{23}$

In the Eq. (8), the value $\left(\mathrm{Z}_{3} \mathrm{e}^{\mathrm{i \alpha} 12}\right)$ is determined in Phase I will be retained in Phase II synthesis process. Prescribed parameter is $\alpha_{23}$ and displacement vector $\delta_{23}$.

The dyad equation of motion is,

$\left(\mathrm{Z}_{4} \mathrm{e}^{\mathrm{i} \beta 12}\right)\left(\mathrm{e}^{\mathrm{i} \beta 23}-1\right)+\mathrm{Z}_{5}\left(\mathrm{e}^{\mathrm{i} \psi 23}-1\right)=\delta_{23}$

Here, in the Eq. (9), $\psi_{23}$ the input crank angle is free choice and $\beta_{23}$ is prescribed. The value $\left(\mathrm{Z}_{4} \mathrm{e}^{\mathrm{i} 12}\right)$ determined in Phase I will be retained and only unknown $\mathrm{Z}_{5}$ will be determined from Eq. (10). $\mathrm{Z}_{5}=\frac{\delta_{23}-\left(\mathrm{Z}_{4} \mathrm{e}^{\mathrm{i} \mathrm{i} 12}\right)\left(\mathrm{e}^{\mathrm{i} \beta 23}-1\right)}{\left(\mathrm{e}^{\mathrm{i} \psi 23}-1\right)}$

\section{OUTPUT OF MECHANISM IN PHASE II}

Since the gear 8 acts as an output link, the synthesis process in Phase I will be carried out only for seven link mechanism. The rotary motion of gear 7 will be transferred to gear 8 and its motion that can be calculated by the Eq. (11). $\mathrm{g}\left(\mathrm{ei}^{\mathrm{\varphi 2} 3}\right)$

In the Eq. (11), $g$ is the vector considered only to represent the position of gear which can be assumed and $\varphi_{23}$ is obtained as gear 7 rotates. Hence gear 8 moves from Position 2(G2) to Position 3(G3). Hence, the link lengths $Z_{5}$ and displacement $\delta_{23}$ are determined in Phase II. Considering all the possibilities, the solution space reduces to $\infty^{2}$ in Phase II. The complete solution space of the synthesis is the summation of solution in both Phases which results in $\infty^{5}$.
The loop closure equation is,

To determine $Z_{1}$

$Z_{2}+Z_{3}-Z_{4}-Z_{5}-Z_{1}=0$

To determine $Z_{9}$

$Z_{5}+Z_{4}-Z_{6}-Z_{7}-Z_{8}-Z_{9}=0$

Thus, all the required parameters are determined.

The conventions followed to indicate links and angles in Phase I and Phase II are listed in Table 1 and summary of Phase I and Phase II for 2 FSP synthesis of motion generation is provided in Table 2.

Table 1 Convention followed to indicate links and angles in Phase I and Phase II

\begin{tabular}{|c|c|c|}
\hline $\begin{array}{l}\text { Link (vector } \\
\text { representation } \\
\text { and angle } \\
\text { between two } \\
\text { different } \\
\text { positions of } \\
\text { link) } \\
\end{array}$ & $\begin{array}{c}\text { Phase I (from } \\
\text { Position 1: } \\
\mathrm{O}_{\mathrm{a}} \mathrm{A}_{1} \mathbf{B}_{1} C_{D_{1}} \mathbf{O}_{\mathrm{e}} \mathrm{O}_{\mathrm{f}}, \\
\text { to } \\
\text { Position 2: } \\
\mathrm{O}_{\mathrm{a}} \mathrm{A}_{2} \mathbf{B}_{2} \mathrm{CD}_{2} \mathrm{O}_{\mathrm{e}} \mathrm{O}_{\mathrm{f}} \text { ) }\end{array}$ & $\begin{array}{c}\text { Phase II (from } \\
\text { Position 2: } \\
\mathrm{O}_{\mathrm{c}} \mathrm{C}_{2} \mathbf{B}_{2} \mathbf{A}_{2} \mathbf{B}_{2} \mathbf{D}_{2} \mathrm{O}_{\mathrm{e}} \mathrm{O}_{\mathrm{f}} \\
\text { to } \\
\text { Position 3: } \\
\mathrm{O}_{\mathrm{c}} \mathrm{C}_{3} \mathbf{B}_{3} \mathbf{A}_{2} \mathbf{B}_{3} \mathbf{D}_{3} \mathrm{O}_{\mathrm{e}} \mathrm{O}_{\mathrm{f}} \text { ) }\end{array}$ \\
\hline $\begin{array}{c}\mathrm{O}_{\mathrm{a}} \mathrm{O}_{\mathrm{c}}, \mathrm{Z}_{1} \text { fixed } \\
\text { link }\end{array}$ & Fixed Link & Fixed Link \\
\hline $\mathrm{O}_{\mathrm{a}} \mathrm{A}, \mathrm{Z}_{2}, \theta$ & $\theta_{12}$ & Temporarily fixed \\
\hline $\mathrm{AB}, \mathrm{Z}_{3}, \alpha$ & $\alpha_{12}$ & $\alpha_{23}$ \\
\hline $\mathrm{CB}, \mathrm{Z}_{4}, \beta$ & $\beta_{12}$ & $\beta_{23}$ \\
\hline $\mathrm{O}_{\mathrm{c}} \mathrm{C}, \mathrm{Z}_{5}, \psi$ & Temporarily fixed & $\psi 23$ \\
\hline $\mathrm{DB}, \mathrm{Z}_{6}, \omega$ & $\omega_{12}$ & $\omega_{23}$ \\
\hline $\mathrm{O}_{\mathrm{e}} \mathrm{D}, \mathrm{Z}_{7}, \gamma$ & $\gamma_{12}$ & $\gamma_{23}$ \\
\hline $\mathrm{O}_{\mathrm{e}} \mathrm{O}_{\mathrm{f}}, \mathrm{Z}_{8}$ & Rigid & Rigid \\
\hline $\begin{array}{l}\text { OfG, g } \\
\text { (Represents } \\
\text { only angular } \\
\text { movement of } \\
\text { Gear 8) } \\
\end{array}$ & $\varphi 12$ & $\varphi 23$ \\
\hline $\begin{array}{l}\text { Displacement } \\
\text { Vector: } \delta\end{array}$ & $\mathrm{B}_{1} \mathrm{~B}_{2}=\delta_{12}$ & $\mathrm{~B}_{2} \mathrm{~B}_{3}=\delta_{23}$ \\
\hline $\begin{array}{c}\text { Sign } \\
\text { Convention }\end{array}$ & $\begin{array}{c}\text { Counter } \\
\text { Clockwise motion } \\
\text { is treated as } \\
\text { positive }\end{array}$ & $\begin{array}{l}\text { Clockwise motion is } \\
\text { treated as negative }\end{array}$ \\
\hline
\end{tabular}

Table 2 Summary of Phase I and Phase II for 2 FSP Synthesis of Motion Generation

\begin{tabular}{|c|c|c|c|}
\hline $\begin{array}{c}\text { Sl. } \\
\text { No. }\end{array}$ & Description & Phase I & Phase II \\
\hline 1 & Link fixed & $\mathrm{O}_{\mathrm{c}} \mathrm{C}$ & $\mathrm{O}_{\mathrm{a}} \mathrm{A}$ \\
\hline 2 & $\begin{array}{c}\text { Prescribed } \\
\text { Parameter }\end{array}$ & $\begin{array}{c}\alpha_{12}, \beta_{12}, \omega_{12}, \\
\delta_{12}, \mathrm{Z}_{2}, \mathrm{Z}_{7}, \\
\mathrm{Z}_{8}\end{array}$ & $\begin{array}{c}\alpha_{23}, \beta_{23}, \\
\omega_{23}, \delta_{23}\end{array}$ \\
\hline 3 & Free Choice & $\theta_{12}, \gamma_{12}$ & $\psi_{23}, \gamma_{23}$ \\
\hline 4 & Unknowns & $\mathrm{Z}_{3}, \mathrm{Z}_{4}, \mathrm{Z}_{6}$ & $\mathrm{Z}_{5}$ \\
\hline 5 & No. of Solutions & $\infty^{2}$ & $\infty^{2}$ \\
\hline 6 & $\begin{array}{c}\text { Total No. of } \\
\text { Solutions }\end{array}$ & \multicolumn{2}{|c|}{$\infty^{4}$} \\
\hline
\end{tabular}




\section{IV.III ADVANTAGE, LIMITATION AND APPLICATION OF THE SYNTHESIZED MECHANISM}

The synthesized mechanism offers an added advantage which can be considered as one of the possibilities in modes of operation. The present mechanism synthesized works with two inputs provided at cranks $\mathrm{O}_{a} \mathrm{~A}$ and $\mathrm{O}_{c} \mathrm{C}$. In Phase $\mathrm{I}_{\mathrm{a}} \mathrm{A}$ is made as input and in Phase $\mathrm{II} \mathrm{O}_{\mathrm{c}} \mathrm{C}$. This requires two motors to run the mechanism with one motor operating in each Phase. This is one of the possible modes of operating the mechanism. Another way of operating the mechanism is through gear 8 working as an input. So this action requires only one motor to be connected to gear 8 which acts as input for both the Phases.

Hence, the synthesized eight link gear mechanism can be made to work in two possible modes of operation. Input motion provided to cranks in respective Phases requiring two motors and input motion provided to gear 8 in both Phases requiring only one motor. These possibilities can be considered as advantages of the designed mechanism.

Some limitations also accompany the synthesized mechanism which needs to be focused on. During the operation of mechanism with cranks as inputs, complete rotation of the cranks may not be possible. Input provided to gear offers a limit in angular rotation to specified angle and direction of motion. Stepper motors may be used to overcome the difficulties in modes of operation to some extent.

The proposed mechanism can be put forward to some industrial applications which are just a sort of thought. The first application being ball painting \& sealing process, which includes paint application to new balls and embossing the company seal on colored balls. Second application dealing with empty bottle filling, capping and sealing process which includes filling of liquid in new empty bottles, fixing caps on the filled bottles and sealing them. In both applications, goods are transferred from conveyers which are at different levels with different operations carried out in between. These applications are discussed in following paragraphs. Fig.4 shows application of the synthesized mechanism for ball painting \& sealing process in Phase I. In this phase, plain white ball from conveyer 1 is transferred to ball coloring station where the ball gets colored. Since this happens to be the first operation, the Phase I operation is repeated to provide continuity of the process initially. Now at the end of this Phase new ball at coloring station gets colored and ball at sealing station gets embossed with company logo.

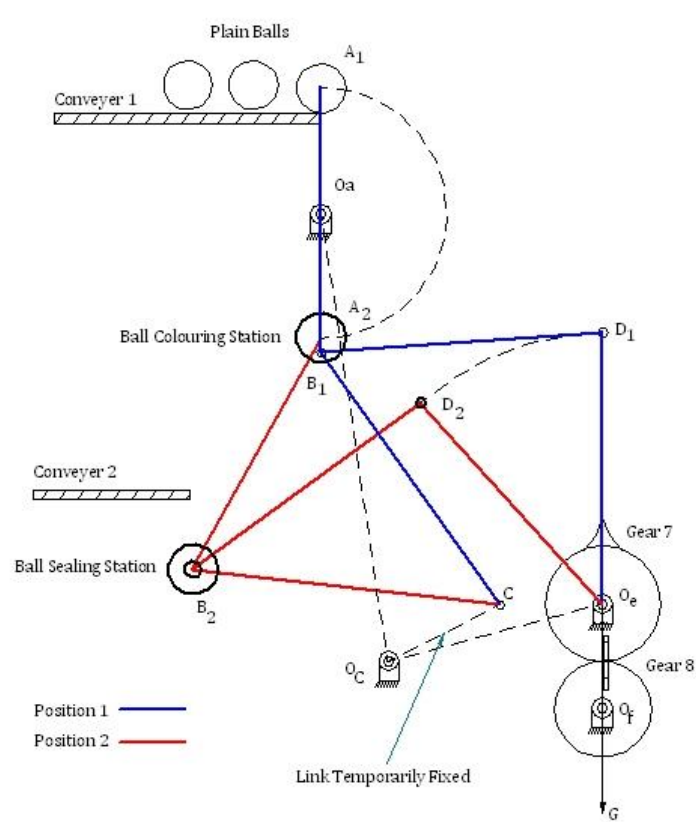

Fig.4 Ball Painting and Sealing Process Phase I
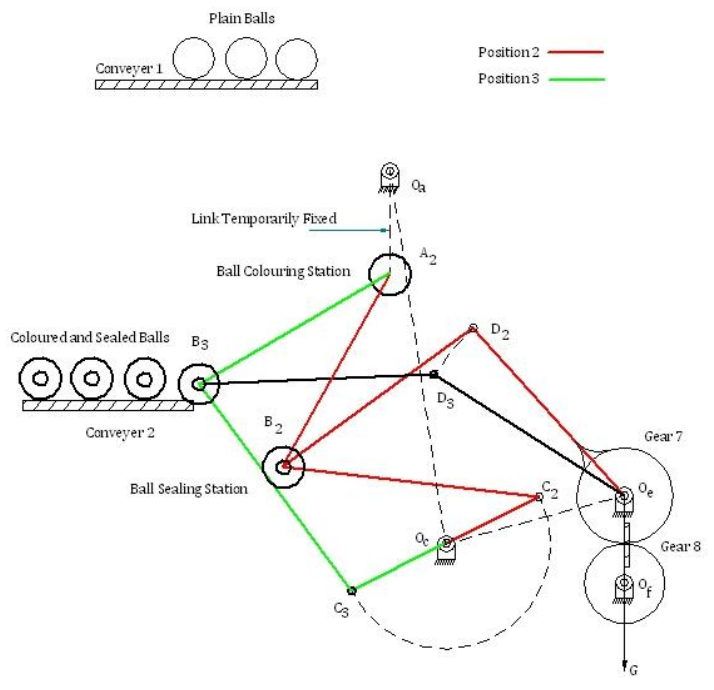

Fig.5 Ball Painting and Sealing Process Phase II

Fig.5 shows the application of the synthesized mechanism for ball painting \& sealing process in Phase II. In this phase, the colored and embossed balls are transferred from ball sealing station to conveyer 2 which carries the balls for further activities like packing or might be a quality check. These operations are repeated and new plain balls are colored, embossed and transferred from conveyer 1 to conveyer 2 in different phases.

Fig.6 shows the application of the synthesized mechanism for bottle filling, capping and sealing process in Phase I. In this phase empty bottles in conveyer 1 reach bottle filling station in which liquid is filled into the empty bottles. When Phase I operation starts, liquid filled bottle from conveyer 1 is transferred to bottle capping station where the filled bottles are capped. Since this 
happens to be the first operation, the Phase I operation is repeated to provide continuity in the process initially. Now at the end of this Phase, filled bottle at capping station gets capped and bottle at sealing station gets sealed on.

Lastly, in Phase II operation (refer Fig.7) sealed bottles from bottle sealing station are transferred to conveyer 2 for packing. Thus these thought of applications may serve the purpose of synthesized mechanism to carry out different tasks in different Phases.

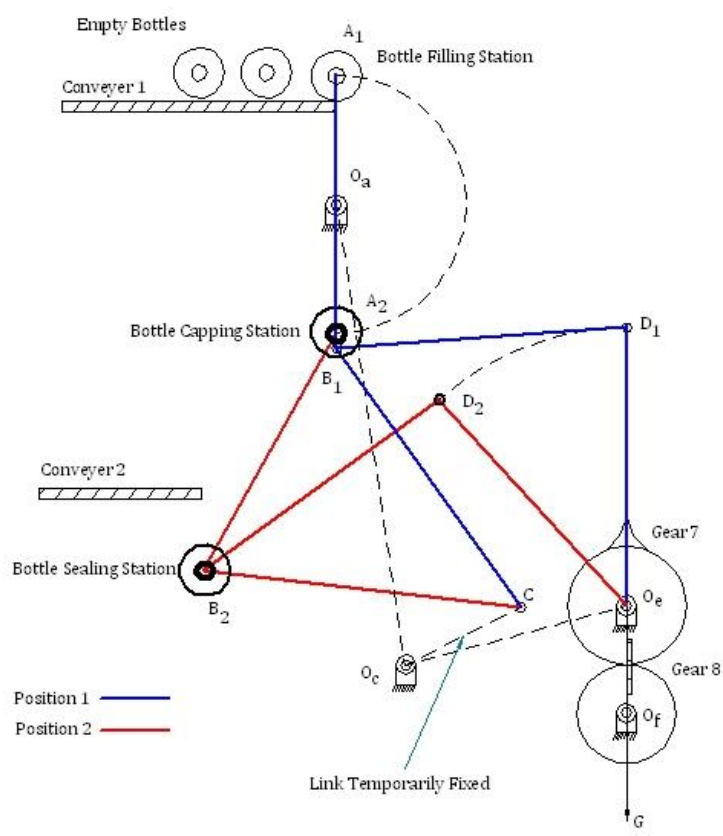

Fig.6 Bottle Filling, Capping and Sealing Process Phase I
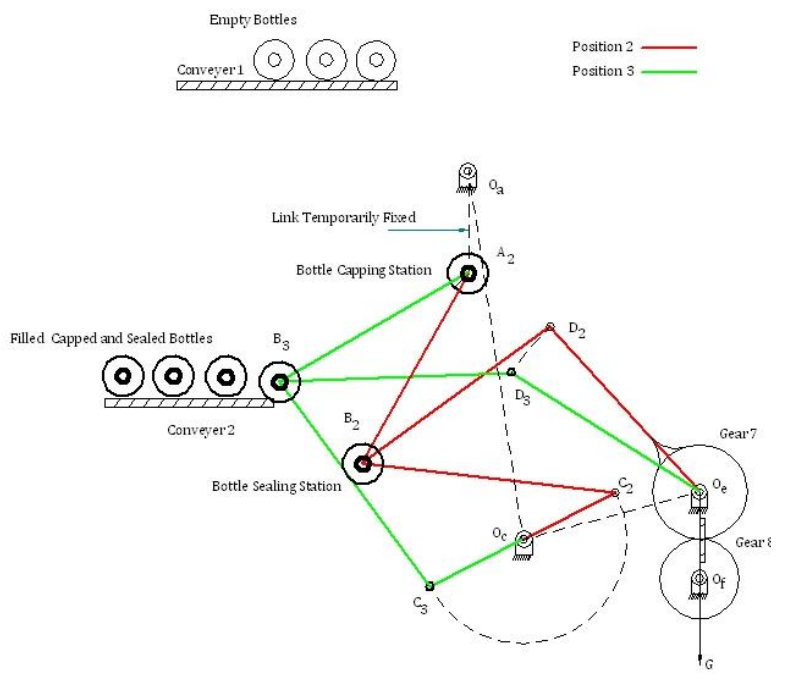

Fig.7 Bottle Filling, Capping and Sealing Process Phase II

\section{AN ILLUSTRATION}

Synthesize an eight link gear mechanism as shown in Fig.1 with variable topology type for the following specifications:

Phase I:

$$
\begin{aligned}
& Z_{2}=0+38 i \\
& \delta_{12}=-40-65 i \\
& Z_{8}=0-32 i \\
& Z_{7}=0+82 i \\
& \theta_{12}=-180^{0} \mathrm{CW} \\
& \gamma_{12}=46^{0} \mathrm{CCW}
\end{aligned}
$$

Phase II:

$\psi_{23}=-180^{\circ} \mathrm{CW}$

\section{SOLUTION:}

\section{SOLUTION FOR PHASE I SYNTHESIS:}

From Eq. (2), $\delta_{12}, Z_{2}$ and $\alpha_{12}$ are prescribed. Free choice made is $\theta_{12}=-30^{\circ} \mathrm{CW}$. Solving the equation determines the value $Z_{3}=-00.522-80.156 i$ Magnitude: $\left|\mathrm{Z}_{3}\right|=\mathrm{AB}=80.1$

From Eq. (4), $\delta_{12}, Z_{7}$ and $\omega_{12}$ are prescribed. Free choice made is $\gamma_{12}=30^{\circ} \mathrm{CCW}$. Solving the equation determines the value $\mathrm{Z}_{6}=-84.0-15.2 \mathrm{i}$ Magnitude: $\left|Z_{6}\right|=D B=85.3$

From Eq. (6), $\delta_{12}$ and $\beta_{12}=49^{0} \mathrm{CCW}$ are prescribed. Solving the equation determines the value $\mathrm{Z}_{4}=-51.30+76.388 \mathrm{i}$

Magnitude: $\left|Z_{4}\right|=C B=92.0$

Hence, link lengths $Z_{3}, Z_{4}$ and $Z_{6}$ are determined in Phase I.

\section{SOLUTION FOR PHASE II SYNTHESIS:}

From Eq. (8), $\alpha_{23}=-27^{0} \mathrm{CW}$ and displacement $\delta_{23}=-26.9+25.9 \mathrm{i}$ are prescribed.

From Eq. (10) $\psi_{23}$ is free choice, $\beta_{23}=$ $45^{\circ} \mathrm{CW}$ and $\delta_{23}$ are prescribed. Solving the equation determines the value $Z_{5}=30.8+17.65 i$ Magnitude: $\left|\mathrm{Z}_{5}\right|=\mathrm{O}_{\mathrm{c}} \mathrm{C}=35.4$

Hence, link length $\mathrm{Z}_{5}$ is determined in Phase II

From Eq. (12) and (13)

$\mathrm{Z}_{1}=19.1-136.1 \mathrm{i}$

Magnitude: $\left|\mathrm{Z}_{1}\right|=\mathrm{O}_{\mathrm{a}} \mathrm{O}_{\mathrm{c}}=137.5$

$\mathrm{Z}_{9}=63.5+27.15 \mathrm{i}$

Magnitude: $\left|\mathrm{Z}_{9}\right|=\mathrm{O}_{\mathrm{c}} \mathrm{O}_{\mathrm{f}}=69.0$ 
Thus, the determined parameters of eight link gear mechanism are,

$$
\begin{aligned}
\left|\mathrm{Z}_{1}\right| & =\mathrm{O}_{\mathrm{a}} \mathrm{O}_{\mathrm{c}}=137.5 \\
\left|\mathrm{Z}_{2}\right| & =\mathrm{O}_{\mathrm{a}} \mathrm{A}=38 \\
\left|\mathrm{Z}_{3}\right| & =\mathrm{AB}=80.1 \\
\left|\mathrm{Z}_{4}\right| & =\mathrm{CB}=92.0 \\
\left|\mathrm{Z}_{5}\right| & =\mathrm{O}_{\mathrm{c}} \mathrm{C}=35.4 \\
\mid \mathrm{Z}_{6} & =\mathrm{DB}=85.3 \\
\mid \mathrm{Z}_{7} & =\mathrm{O}_{\mathrm{e}} \mathrm{D}=82 \\
\left|\mathrm{Z}_{8}\right| & =\mathrm{O}_{\mathrm{f}} \mathrm{O}_{\mathrm{e}}=32 \\
\left|\mathrm{Z}_{9}\right| & =\mathrm{O}_{\mathrm{c}} \mathrm{O}_{\mathrm{f}}=69.0
\end{aligned}
$$

\section{CONCLUSION}

An eight link gear mechanism is synthesized analytically using the concept of variable topology operating in two phases. This mechanism operates as a seven link gear mechanism in each phase. These seven link gear mechanism portion of eight link gear mechanism are designed for two finitely separated positions. The synthesized mechanism offers an added advantage in possible modes of operating the mechanism and may find its application in industrial sector. The applications discussed are some of the thoughts that may be implemented by small scale industries. Hence, with all the mentioned possibilities variable topology focuses on a non iterative and simplified method in mechanism synthesis process.

\section{REFERENCES}

[1] Balli S. Shrinivas and Chand Satish, (2001), 'Synthesis of a five-bar mechanism with variable topology for motion between extreme positions (SYNFBVTM),' Mechanism and Machine Theory, vol. 36, no.10, pp. 1147-1156.

[2] Balli S. Shrinivas and Chand Satish, (2002), 'Five-bar motion and path generators with variable topology for motion between extreme positions,' Mechanism and Machine Theory, vol. 37, no. 11, pp. 1435-1445.

[3] Balli S. Shrinivas and Chand Satish, (2003), 'Synthesis of a planar seven-link mechanism with variable topology for motion between two deadcenter positions,' Mechanism and Machine Theory, vol.38, no. 11, pp. 1271-1287.

[4] Gadad G. M., Daivagna M. Umesh and Balli S. Shrinivas, (2005), 'Triad and dyad synthesis of planar seven-link mechanisms with variable topology', National Conference on Machines and Mechanisms (NaCoMM '05), pp. 67-73.

[5] Daivagna M. Umesh and Balli S. Shrinivas, (2007), 'FSP Synthesis of an off-set five bar-slider mechanism with variable topology', National Conference on Machines and Mechanisms (NaCoMM '07), pp. 345-350.
[6] Ren-Chung Soong, Kuei-Shu Hsu and FengTsai Weng, (2008), 'A Programmable Geared Seven-bar Mechanism for Mechanical Forming Presses', Journal of the Chinese Society of Mechanical Engineers, Vol.29, No.1, pp.61-67.

[7] Daivagna M. Umesh and Balli S. Shrinivas, (2010), 'Synthesis of a Seven-Bar Slider Mechanism with Variable Topology for Motion between Two Dead-Center Positions', World Congress on Engineering, Vol. II, pp. 1454-1459.

[8] Parlaktas Volkan, Soylemez Eres and Tanik Engin, (2010), 'On the synthesis of a geared fourbar mechanism', Mechanism and Machine Theory, Vol.45, no. 8, pp.1142-1152.

[9] Daivagna M. Umesh and Balli S. Shrinivas, (2011), 'Synthesis of Five-Bar Slider Mechanism with Variable Topology for Finitely Separated Positions', Advances in Mechanical Engineering, vol.2011, https://doi.org/10.1155/2011/697316.

[10] Tadalagi B. Prashant and Balli S. Shrinivas, 'A Review on Mechanisms with Variable Topology (Revisiting the Variable Topology Mechanism)', (2019), IOP Conf. Series: Materials Science and Engineering, vol. 691, pp. 012047(19).

[11] George N. Sandoor and Arthur G. Erdman, (1984), Advanced Mechanism Design: Analysis and Synthesis, Vol. II, Prentice-Hall, Englewood Cliffs, New Jersey.

[12] Rawat Y. R. (1996), 'Synthesis of Variable Topology Mechnaisms', M.Tech, Dissertation, Mechanical Engineering Department, IIT, Bombay. 